\title{
Classification of NFC Applications in Diverse Service Domains
}

\author{
Busra Ozdenizci, Mohammed Alsadi, Kerem Ok, and Vedat Coskun
}

\begin{abstract}
NFC (Near Field Communication) technology allows people to integrate their daily-use loyalty cards, credit cards etc. into their mobile phones. In addition to integrating those cards into mobile devices, NFC technology brings innovation opportunities to mobile communications. It enables two users to easily communicate and exchange data simply by touching two mobile phones to each other. The aim of this paper is to perform a brief review of the published NFC applications in literature and explored the benefits of these applications by classifying them in eight service domains. We believe that this analysis will provide valuable insights for performing rigorous and business relevant research on NFC applications and its service domains.
\end{abstract}

Index Terms - NFC, review, applications, service domains, classification, benefits.

\section{INTRODUCTION}

NFC as one of the enablers for ubiquitous computing is a combination of contactless identification technologies which requires bringing two NFC compatible devices close to each other, essentially touching them (Fig. 1). User first interacts with a smart object (either an NFC tag, NFC reader, or another NFC enabled mobile phone) using her NFC enabled mobile phone (NFC mobile). After touching occurs, NFC mobile can make use of received data, or can use provided mobile services such as opening a web page, making a web service connection etc.

NFC is a bidirectional short range, wireless communication technology. The communication occurs between two near devices within few centimeters. $13.56 \mathrm{MHz}$ signal with a bandwidth not more than $424 \mathrm{Kbit} / \mathrm{s}$ is used. NFC technology is based on Radio Frequency Identification (RFID) technology and can operate in card emulation, reader/writer, and peer-to-peer operating modes where communication occurs between a mobile phone on one side, and an NFC reader, a passive RFID tag (NFC tag), or a mobile phone on the other side respectively [1].

Up to now, many NFC trials are conducted over the world, especially in payment domain. All trials conclude the fact that with the development of NFC technology, mobile phone is subject to become safer, more convenient, speedier and more fashionable physical instrument.

Manuscript received January 31, 2013; revised April 20, 2013

The authors are with the NFC Lab - ISTANBUL in Department of Information Technologies of ISIK University, Turkey (e-mail: vedatcoskun@isikun.edu.tr, busraozdenizci@isikun.edu.tr,

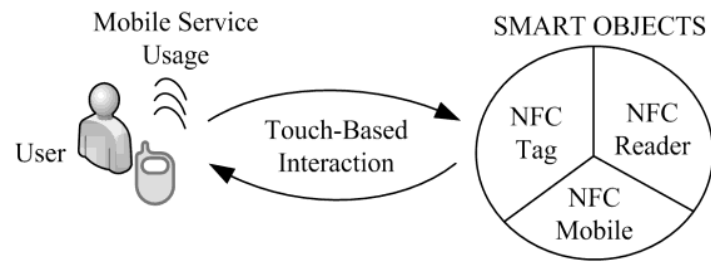

Fig. 1. Touch based interaction.

Since NFC technology is started to be promoted, various real-life applications have been evolved. At the same time, NFC has become an attractive research area for many academicians due to its exploding growth and its promising applications and related services.

The purpose of this paper is to conduct a brief review of published NFC applications in literature and categorize these applications according to their service domains. This analysis will provide us valuable insights for performing rigorous and business relevant research on NFC applications and its service domains. Also we have exposed some challenging research issues on NFC applications for future research.

\section{REVIEW OF NFC APPLICATIONS}

NFC technology covers a wide range of applications and these applications provide real implementations or prototypes with experimental evaluations or testing studies. In this research, we investigate NFC applications in service domain perspective. We reviewed 78 papers that proposes or explores new NFC applications and published up to 2012.

Since NFC applications became an attractive research area, several promising applications are proposed up to now. Some studies have observed NFC applications according to their operating modes [2], [3]. With the exploding growth of NFC applications, the proposed NFC applications in one service domain may operate in one of the operating mode or may support more than one operating mode. Thus, observing NFC applications in service domain aspect provide us more challenging insights.

After review of NFC applications, we grouped NFC applications under 8 service domains:

1. Healthcare Services

2. Smart Environment Services

3. Mobile Payment, Ticketing and Loyalty Services

4. Entertainment Services

5. Social Network Services

6. Educational Services

7. Location Based Services

8. Work Force and Retail Management Services

Fig. 2 shows the distribution of NFC papers that are

keremok@isikun.edu.tr). 
proposing or exploring NFC applications according to the service domains. As seen from the figure, approximately $21 \%$ of the published papers on NFC applications are proposals for developing smart environment. Then developing NFC enabled mobile payment, ticketing and loyalty systems (17\%) and NFC enabled healthcare systems (18\%) comes with similar levels.

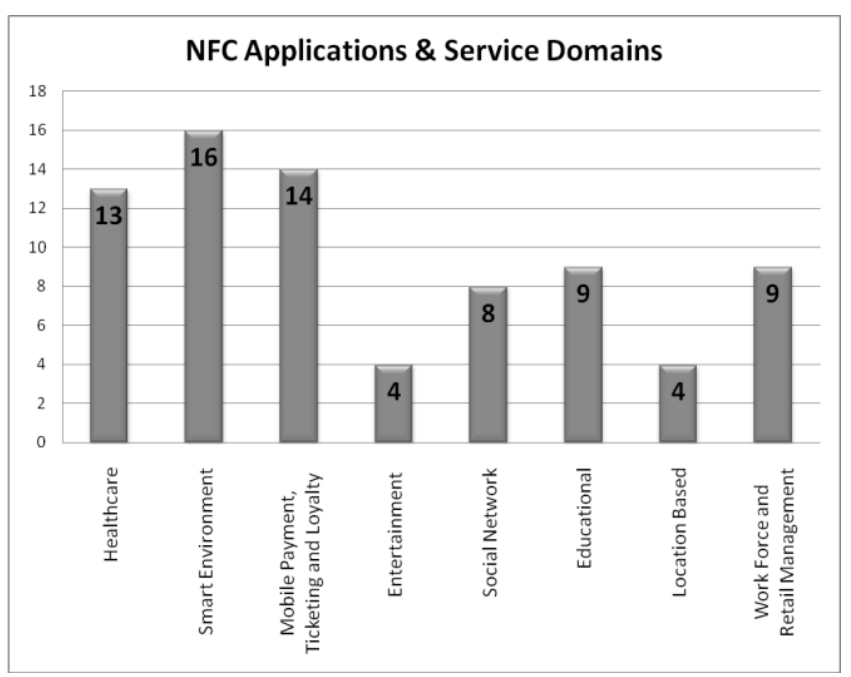

Fig. 2. Distribution of NFC applications.

\section{NFC APPLICATIONS AND SERVICE DOMAIN ANALYSIS}

In this part, we have presented the services domains of NFC technology and we reviewed published NFC papers in those service domains. At the same time, we have briefly explained the benefits of proposed NFC applications.

\section{A. Healthcare Services}

In the last decades, one of the fields where IT is playing fundamental role is healthcare. Providing effective and appropriate healthcare services is one of the most important objectives of information and communication technologies. It is seen from the literature that NFC plays significant role in health service domain due to its easy use with lower consumption property. NFC provides user-friendly remote health monitoring, controlling, and tracking systems [4]-[9], and electronic data capturing services [10]-[12]. There are also some services that aim to improve the care dependent people's quality of life such as NFC enabled prescription system [13], storage of encrypted medical data on tags [14], adverse drugs reaction and allergy detection systems in pharmaceutical and medical care [15], [16].

\section{B. Smart Environment Applications}

In technological perspective, smart environment is defined in [17] as "a physical world that is richly and invisibly interwoven with sensors, actuators, displays, and computational elements and also embedded seamlessly in the everyday objects of our lives, and connected through a continuous network". NFC technology can be also buried in applications that address diverse and heterogeneous needs and capabilities of users in the real world, and make users' life easier.

Most of the smart environments are enabled by NFC tags that are distributed around (Fig. 3). In accordance with [18], “tags can provide support in user's everyday life activities by establishing a bridge between the physical and digital worlds when they are ubiquitous in the everyday environments of users" and "the tags become an integral part of physical space, altering the way humans perceive and behave in it".

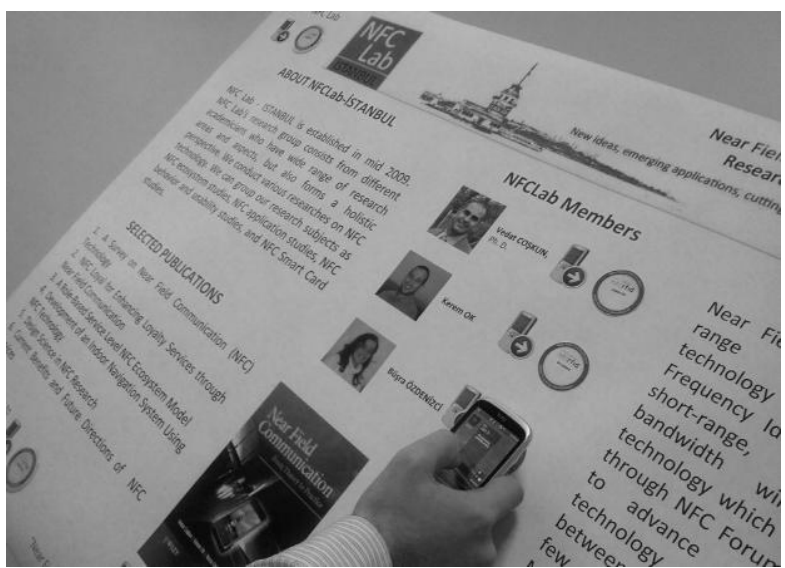

Fig. 3. Smart poster application.

It is possible to see innovative examples of smart environment in the NFC literature, which makes use of NFC tags to simplify utilization of existing functions of a system [19], to control a system and perform services remotely [17], [18], [20]-[24] and also to provide information channel [25]-[31]. N-CASH is another example for NFC enabled smart environment [32], [33] that clearly describes the creation of a smart space, which can be activated by NFC mobile to control devices such as home appliances. The appliances are controlled and driven by the request from NFC mobile that uses predefined ontology and rule based reasoning. So, NFC mobile acts as the key to enter the space as well as provide personalized control of a variety of appliances in that space.

\section{Mobile Payment, Ticketing and Loyalty Services}

With the market and technological developments, successful mobile payment solutions have already been launched over the world. Actually some countries are much more advanced in terms of deployed technology and implemented business cases since governments and influential mobile network operators (MNOs) in those countries have powerful impact on enhancing the development of mobile payment services [34]. Various technologies contributed for the development of mobile payment systems such as RFID technology, contactless smart cards, Short Message Service (SMS), USSD (Unstructured Supplementary Service Data (USSD), WAP (Wireless Application Protocol) IVR (Interactive Voice Response) and so on.

Currently, integration of NFC technology with mobile payment systems brought new and innovative business solutions. Payment, ticketing and loyalty applications are possibly the most well-known and promising everyday applications of NFC technology and have the most complexity in ecosystem aspect as well. Thus it can be seen that most of the trials and projects (e.g., Payez Mobile Project [35], Pay-Buy-Mobile Project [36], SIESTA Project [37]) are implemented in this application domain. 
Some of these projects still continue with growing participating entities. From the academic point of view, some valuable studies have been performed as well as some fruitful usability and user experience analyses in payment and payment related application domains. Important examples are:

- An automated reservation and ticketing service for tourists, and a system for car parking access and payment system for ticketing [37], [38],

- Virtual ticketing system and secure mCoupon protocol [39]-[41],

- Secure payment service by Smart Touch Project [42],

- NFC Ticketing system with a simple architecture, including usability testing [43],

- NFC Loyal system including a secure data exchange model to promote payment and loyalty applications on secure elements [44] (Figure 4),

- Offline Tapango system for electronic ticketing process including comparison with traditional paper ticketing process [45],

- Offline NFC payment service with electronic vouchers [46],

- Secure payment system built on a Service Oriented Architecture (SOA) including payment authorization process [47].

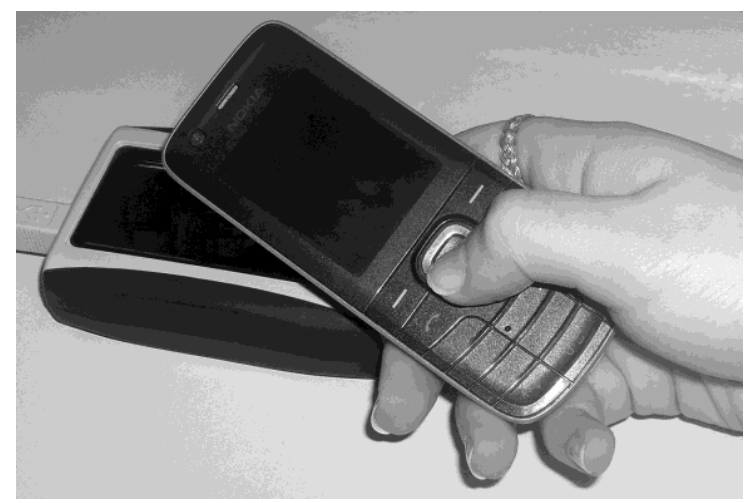

Fig. 4. NFC loyal application.

\section{Entertainment Services}

Although NFC technology has high potential for applications like payment and ticketing, applying NFC technology in entertainment and social media applications is receiving more and more attention on user side. Some examples from the literature are Pass the Bomb and Exquisite Touch games [48] which are implemented with a multi-player purpose; Whack-a-Mole game [49], [50] which combines dynamic NFC displays to explore mobile interaction with tagged, physical objects can leverage mobile gaming; PhonePhone as an NFC enabled musical instrument [51].

\section{E. Social Network Services}

Currently, Internet based social network applications are booming with popular services like Facebook, LinkedIn, MySpace and Twitter etc. NFC technology is also an enabler for social networking tools and can be integrated with the existing social network applications [52]-[55]. Generally, these applications enable users to interact with tagged physical objects and publish information with the virtual world. Some trials are also using peer-to-peer mode to allow users to share and access their personal information, to create friendships in a more tangible and user-friendly way [56]-[58]. Another good way of promoting social network services is to provide also advertising and location based services such as TaggyNet [59].

\section{F. Educational Services}

Currently, universities and schools became a valuable research area for development and testing NFC technology. Various implementations of NFC services and prototypes in universities can be seen to create smart environments for the students as well as to perform efficient work force management and easier administration services for the staff. Up to now, diverse innovative NFC services in university settings are tested and implemented [60]-[63] such as identification, payment services in university cafes and restaurants, photocopy services, reservation and payment of sports facilities, and also resources control and management services, teaching services, dissemination of information and accessing to services.

Also NFC technology can be used in interactive learning process of students [64], [65]. For example, the proposed Moodle system in [64] enables use of games in teaching and learning process. It brings together the characteristics of a common strategy game with an evaluation system; and enables to motivate and reward students by using NFC mobiles.

Other valuable examples related with the efficient work force management in school settings are NFC enabled attendance supervision system [66], [67], and examination systems supported by NFC technology in universities [68].

\section{G. Location Based Services}

Location based services (LBSs) are used for enabling an information service by using the geographical position of the user's mobile device. With the integration of LBSs with NFC technology, users' behavior can be tracked and user experiences can be improved [69], [70]. Depending on the position of the user, most common examples are displaying friends nearby, broadcasting advertisement of stores nearby through SMS/MMS, and discovering nearest post office depending on our geographical position. Hence these services provide location based, customized messages or information to users [69], [71]. Such services can also be integrated with NFC enabled the indoor navigation systems [72], [70] to provide more value added services to the users, especially in shopping centers.

\section{H. Work Force and Retail Management Services}

Furthermore NFC technology contributes in solving the problems within the business world and work force management. For example, in retail industry, retailers face various problems in sales data management such as high cost, low security, and poor performance of real-time documentation [73]-[75]. Nowadays, it is possible to see the advantages of NFC technology in improving the existing business processes within companies [76]-[81]. 


\section{Evaluation}

Each NFC application provides different benefits and underlying values for its user. Also, the study in [3] performed valuable review of literature and exploration of NFC applications' benefits by classifying them into their operating modes (e.g., read/writer operating mode, card emulation operating mode, peer-to-peer operating mode).

In this part, we have summarized the benefits of NFC applications by classifying them in 8 service domains and explored the underlying values in a wide perspective. As seen in Table I, we provide a summary of NFC applications' benefits in terms of their service domains.

TABLE I: SERVICE DOMAINS AND VALUES PROVIDED BY NFC APPLICATIONS

$\begin{array}{ll} & \text { Improve quality of life } \\ \text { Healthcare Services } & \text { Increases mobility } \\ & \text { Decreases physical effort } \\ & \text { Efficient data capturing and tracking }\end{array}$
Services

Easy to implement

Device pairing

Easy information sharing

Easy access to real-time information

Ability to be adapted by many scenarios

$\begin{array}{ll}\text { Mobile Payment, } & \text { Physical object elimination } \\ \text { Ticketing and Loyalty } & \text { Easy access control } \\ \text { Services } & \text { Secure data exchange } \\ & \text { Secure authorization systems }\end{array}$

Entertainment

Easy data exchange

Services

Efficient mobile interaction

Ability to be adapted by many scenarios

Easy share of information

Social Network $\quad$ Easy access to real-time information

Services Real-time updating of data

Increases mobility

Dissemination of information

Efficient resource control and

management

Access control
Value added and customized services Easy access and share of information Improve quality of life

\section{CONCLUSION}

NFC technology simplifies the human environment interaction in diverse service domains and enables users only to touch their NFC mobiles in order to trigger intelligent services.

Several proposals and examples of NFC applications are reviewed in literature, categorized and presented in this brief survey to point out the NFC application's benefits in diverse service domains. Such a categorization provides valuable insights about the technology's development in that service domain, usability, adoption and acceptance issues.

It is seen that some service domains (e.g., entertainment, social network, education, location based services, work force and retail management), still needs more rigorous studies in NFC technology perspective. The benefits of NFC technology in those service domains need to be searched and explored by researchers.

We also explored some open research issues that can be observed by academicians or practitioners:

- Comparison of vulnerabilities of NFC applications in different service domains,

- Analysis of compatibility and interoperability of different NFC mobile architectures in a service domain,

- Development of design principles, methodologies and models for building specific applications such as context aware or smart environment,

- Creation of user interaction models for different service domains,

- Exploration of user perception and preferences for NFC systems,

- Identification of barriers to and critical success factors for NFC adoption,

- Exploration of different cultures and cultural norms impact on NFC usability case studies,

- Exposure of psychological and relational issues in NFC adoption,

- Implementation of longitudinal field studies on NFC usability with well-structured statistical results.

\section{ACKNOWLEDGMENT}

The comprehensive list of all reviewed 78 papers that corresponds to categorization scheme can be found at http://nfclab.isikun.edu.tr/icfcc2013/.

\section{REFERENCES}

[1] V. Coskun, B. Ozdenizci, and K. Ok, "A Survey on Near Field Communication (NFC) Technology," Journal of Wireless Personal $\begin{array}{lll}\text { Communications, } & \text { Published } \quad \text { Online, }\end{array}$ 10.1007/s11277-012-0935-5.

[2] B. Ozdenizci et al., "NFC Research Framework: A Literature Review and Future Research Directions," in Proc. 14th International Business Information Management Association Conference on Global Business Transformation through Innovation and Knowledge Management, Istanbul, Turkey, pp. 2672-2685

[3] K. Ok, "Current Benefits and Future Directions of NFC Services," in Proc. IEEE International Conference on Education and Management Technology, Cairo, Egypt, pp. 334-338.

[4] J. Bravo et al., "Enabling NFC Technology for Supporting Chronic Diseases: A Proposal for Alzheimer Caregivers," in Proc. the European Conference on Ambient Intelligence, pp. 109-125.

[5] J. Bravo et al., "Enabling NFC Technology to Support Activities in an Alzheimer's Day Center," in Proc. the 1st international conference on Pervasive Technologies Related to Assistive Environments, Athens, Greece, 2008. 
[6] J. Bravo et al., "Identification Technologies to Support Alzheimer Contexts," in Proc. the 1st international conference on Pervasive Technologies Related to Assistive Environments, Athens, Greece, 2008.

[7] R. Iglesias et al., "Experiencing NFC-based Touch for Home Healthcare," in Proc. the 2nd International Conference on Pervasive Technologies Related to Assistive Environments, Corfu, Greece, 2009.

[8] C. A. Opperman et al., "A Generic NFC-enabled Measurement System for Remote Monitoring and Control of Client-side Equipment," in Proc. 3rd International Workshop on Near Field Communication, Hagenberg, Austria, pp. 44-49, 2011

[9] E. Strömmer et al., "Application of Near Field Communication for Health Monitoring in Daily Life," in Proc. 28th Annual International Conference of the IEEE Engineering in Medicine and Biology Society, New York City, USA, pp. 3246-3249, 2006.

[10] J. Morak, D. Hayn, P. Kastner, M. Drobics, and G. Schreier, "Near Field Communication Technology as the Key for Data Acquisition In Clinical Research," in Proc. the 1st International Workshop on Near Field Communication, Hagenberg, Austria, pp. 15-19, 2009.

[11] J. Morak, V. Schwetz, D. Hayn, F. Fruhwald, and G. Schreier, "Electronic Data Capture Platform for Clinical Research based on Mobile Phones and Near Field Communication Technology," in Proc. the 30th Annual International Conference of the IEEE Engineering in Medicine and Biology Society, Vancouver, Canada, pp. 5334-5337, 2008.

[12] A. Prinz et al., "inSERT - An NFC-based Self Reporting Questionnaire for Patients with impaired fine motor skills," in Proc. 3rd International Workshop on Near Field Communication, Hagenberg, Austria, pp. 26-31, 2011.

[13] M. Vergara, P. Díaz-Hellín, J. Fontecha, R. Hervás, C. Sánchez-Barba, C. Fuentes, and J. Bravo, "Mobile Prescription: An NFC-Based Proposal for AAL," in Proc. the 2nd International Workshop on Near Field Communication, Monaco, pp. 27-32, 2010.

[14] S. Dünnebeil et al., "Encrypted NFC emergency tags based on the German Telematics Infrastructure," in Proc. of 3rd International Workshop on Near Field Communication, Hagenberg, Austria, pp. 50-55, 2011.

[15] A. J. Jara et al., "A Pharmaceutical Intelligent Information System to Detect Allergies and Adverse Drugs Reactions based on Internet of Things," in Proc. 8th IEEE International Conference on Pervasive Computing and Communications Workshops, Mannheim, pp. 809-812, 2010.

[16] J. Jara et al., "Drugs Interaction Checker based on IoT," in Proc. of Internet of Things, Tokyo, pp. 1-8, 2010.

[17] I. Sanchez, J. Riekki, and M. Pyykkonen, "Touch \& Compose: Physical User Interface for Application Composition in Smart Environments," in Proc. the First International Workshop on Near Field Communication, Hagenberg, Austria, pp. 61-66, 2009.

[18] M. Isomursu, "Tags and the City," PsychNology Journal, vol. 6, no. 2 pp. 131-156, 2008.

[19] R. Steffen, J. Preißinger, T. Schöllermann, A. Müller, and I. Schnabel, "Near Field Communication (NFC) in an Automotive Environment," in Proc. the 2nd International Workshop on Near Field Communication, Monaco, pp. 15-20, 2010.

[20] I. Cappiello, S. Puglia, and A. Vitaletti, "Design and Initial Evaluation of a Ubiquitous Touch-Based Remote Grocery Shopping Process," in Proc. the 1st International Workshop on Near Field Communication, Hagenberg, Austria, pp. 9-14, 2009.

[21] T. Pering et al., "Gesture Connect: Facilitating Tangible Interaction With a Flick Of The Wrist," in Proc. the 1st International Conference on Tangible and Embedded Interaction, pp. 259-262, 2007.

[22] I. Sánchez, M. Cortés, and J. Riekki, "Controlling Multimedia Players using NFC Enabled Mobile Phones," in Proc. of the 6th International Conference on Mobile and Ubiquitous Multimedia, Oulu, Finland, pp. 118-124, 2007.

[23] I. Sánchez et al., "Touch \& Control: Interacting with Services by Touching RFID Tags," in Proc. the 2nd International Workshop on RFID Technology - Concepts, Applications, Challenges (IWRT 08), 2008.

[24] E. Siira and J. Haikio, "Experiences from Near-Field Communication (NFC) in a Meal Service System," in Proc. 1st Annual RFID Eurasia, Istanbul, Turkey, pp. 1-6.

[25] M. Blöckner et al., "Please Touch the Exhibits! Using NFC-based Interaction for Exploring a Museum," in Proc. the 11th International Conference on Human-Computer Interaction with Mobile Devices and Services, Bonn, Germany, 2009

[26] J. Büttgen et al., "Mobile Interaction with an NFC-based Billboard," in Adjunct Proc. of the 11th International Conference on
Human-Computer Interaction with Mobile Devices and Services, Bonn, Germany, 2009

[27] R. Hardy and E. Rukzio, "Touch \& Interact: Touch-based Interaction of Mobile Phones with Displays," in Proc. the 10th International Conference on Human Computer Interaction with Mobile Devices and Services, pp. 245-254, 2008.

[28] R. Hardy and E. Rukzio, "Touch \& Interact: Touch-based Interaction with a Tourist Application," in Proc. the 11th International Conference on Human-Computer Interaction with Mobile Devices and Services, Bonn, Germany, 2009.

[29] W. Rudametkin et al., "NFCMuseum: an Open-Source Middleware for Augmenting Museum Exhibits," Advanced Sensors and lightweight Programmable middleware for Innovative RFID Enterprise Applications, 2008

[30] U. Sandner et al., "News-on-the-Go.," in Proc. Mobile HCI'07, Singapore, pp. 361-363, 2007.

[31] P. Dobrigkeit et al., "Exchange of contact data between mobile phones using NFCIP," in Proc. 4th European Workshop on RFID Systems and Technologies, Freiburg, Germany, pp. 1-9, 2008.

[32] Y. Chang, C. Chang, Y. Hung, and C. Tsai, "NCASH: NFC Phone-Enabled Personalized Context Awareness Smart-Home Environment," Journal of Cybernetics and Systems, vol. 41, no. 2, pp. 123-145, 2010.

[33] Y. Chang et al., "Toward a NFC phone-Driven Context Awareness Smart Environment," in Proc. Symposia and Workshops on Ubiquitous, Autonomic and Trusted Computing, Brisbane, QLD, pp. 298-303, 2009.

[34] J. Ondrus and Y. Pigneur, "An Assessment of NFC for Future Mobile Payment Systems." in Proc. the International Conference on the Management of Mobile Business, pp. 43, 2007.

[35] Payez Mobile. [Online]. Available: http://www.payezmobile.com

[36] GSMA, Pay-Buy Mobile Business Opportunity Analysis, Version 1.0, White Paper, 2007.

[37] D. Baldo, G. Benelli, and A. Pozzebon, "The SIESTA project: Near Field Communication, based applications for tourism," in Proc. 7th International Symposium on Communication Systems Networks and Digital Signal Processing, Newcastle upon Tyne, pp. 721 - 725, 2010

[38] G. Benelli and A. Pozzebon, "An Automated Payment System for Car Parks Based on Near Field Communication Technology," in Proc. International Conference for Internet Technology and Secured Transactions (ICITST), London, pp. 1-6, 2010.

[39] M. Aigner, S. Dominikus, and M. Feldhofer, "A System of Secure Virtual Coupons Using NFC Technology," in Proc. Fifth Annual IEEE International Conference on Pervasive Computing and Communications Workshops, pp. 362-366, 2007.

[40] S. Dominikus and M. Aigner, "mCoupons: An Application for Near Field Communication (NFC)," in Proc. 21st International Conference on Advanced Information Networking and Applications Workshops, Niagara Falls, pp. 421-428, 2007.

[41] H. C. Hsiang et al., "A Secure Mcoupon Scheme Using Near Field Communication," International Journal of Innovative Computing, Information and Control, vol. 5, no. 11, 2009.

[42] M. Pasquet et al., "Secure Payment With NFC Mobile Phones In The Smart Touch Project," in Proc. International Symposium on Collaborative Technologies and Systems, Irvine, CA, pp. 121-126, 2008.

[43] S. L. Ghiron, S. Sposato, C. M. Medaglia, and A. Moroni, "NFC ticketing: A Prototype and Usability Test of an NFC-based Virtual Ticketing Application," in Proc. the First International Workshop on Near Field Communication, Hagenberg, Austria, pp. 45-50, 2009.

[44] B. Ozdenizci, V. Coskun, M. Aydin, and K. Ok, "NFC Loyal: A Beneficial Model to Promote Loyalty on Smart Cards of Mobile Devices," in Proc. IEEE International Conference for Internet Technology and Secured Transactions, London, pp. 134-139, 2010

[45] J. Neefs, F. Schrooyen, and J. Doggen, "Paper ticketing vs. Electronic Ticketing based on off-line system 'Tapango'," in Proc. the Second International Workshop on Near Field Communication, Monaco, pp. 3-8.

[46] G. Damme et al., "Offline NFC Payments with Electronic Vouchers," in Proc. the 1st ACM workshop on Networking, systems, and applications for mobile handhelds, pp. 25-30, 2009.

[47] K. S. Kadambi et al., "Near-Field Communication-Based Secure Mobile Payment Service," in Proc. the 11th International Conference on Electronic Commerce, pp. 142-151, 2009.

[48] A. Nandwani et al., "NFC Mobile Parlor Games Enabling Direct Player to Player Interaction," in Proc. 3rd International Workshop on Near Field Communication, Hagenberg, Austria, pp. 21-25, 2011. 
[49] G. Broll et al., "Touch to Play - Mobile Gaming with Dynamic, NFC-based Physical User Interfaces," in Proc. the 12th international conference on Human computer interaction with mobile devices and services, Lisboa, 2010.

[50] G. Broll et al., "Touch to Play - Exploring Touch-Based Mobile Interaction with Public Displays," in Proc. 3rd International Workshop on Near Field Communication, Hagenberg, Austria, pp. 15 $-20,2011$.

[51] R. Ivanov, "Indoor Navigation System for Visually Impaired," in Proc. International Conference on Computer Systems and Technologies, Sofia, Bulgaria, 2010.

[52] J. Haikio, T. Tuikka, E. Siira, and V. Tormanen, "Would You Be My Friend? - Creating a Mobile Friend Network with 'Hot in the City'," in Proc. the 43rd Hawaii international conference on system sciences, Hawaii, USA, pp. 1-10, 2010.

[53] R. Hardy et al., "MyState: Using NFC to Share Social and Contextual Information in a Quick and Personalized Way," in Proc. the 12th ACM International Conference Adjunct Papers on Ubiquitous Computing, Copenhagen, Denmark, pp. 447-448, 2010.

[54] F. Köbler, P. Koene, H. Krcmar, M. Altmann, and J. M. Leimeister, "LocaTag - An NFC-Based System Enhancing Instant Messaging Tools with Real-Time User Location," in Proc. the 2nd International Workshop on Near Field Communication, Monaco, pp. 57-61, 2010.

[55] E. Siira and V. Törmänen, "The Impact of NFC on Multimodal Social Media Application," in Proc. the 2nd International Workshop on Near Field Communication, Monaco, pp. 51-56, 2010.

[56] A. Fressancourt, C. Herault, and E. Ptak, "NFCSocial: Social Networking in Mobility Through IMS and NFC," in Proc. the 1st International Workshop on Near Field Communication, Hagenberg, Austria, pp. 24-29, 2009.

[57] J. Haikio, T. Tuikka, E. Siira, and V. Tormanen, "Would You Be My Friend? - Creating a Mobile Friend Network with 'Hot in the City'," in Proc. the 43rd Hawaii international conference on system sciences, Hawaii, USA, pp. 1-10, 2010.

[58] E. Siira and V. Törmänen, "The Impact of NFC on Multimodal Social Media Application," in Proc. the 2nd International Workshop on Near Field Communication, Monaco, pp. 51-56, 2010.

[59] H. Aziza, "NFC Technology in Mobile Phone Next-Generation Services," in Proc. the 2nd International Workshop on Near Field Communication, Monaco, pp. 21-26, 2010.

[60] S. Miranda and N. Pastorelly, "NFC mobiquitous information service prototyping at the University of Nice Sophia Antipolis and multi-mode NFC application proposal," in Proc. the 3rd International Workshop on Near Field Communication, Hagenberg, Austria, pp. 3-8, 2011.

[61] G. M. Miraz, I. L. Ruiz, and M. A. Gomez-Nieto, "How NFC can be used for the Compliance of European Higher Education Area Guidelines in European Universities," in Proc. the 1st International Workshop on Near Field Communication, Hagenberg, Austria, pp. 3-8, 2009.

[62] G. M. Miraz, I. L. Ruiz, and M. Á. Gómez-Nieto, "University of Things: Applications of Near Field Communication Technology in University Environments," Journal of E-working, vol. 3, no. 1, pp. 52-64, 2009.

[63] I. Ruiz et al., "University Smart Poster: Study of NFC Technology Applications for University Ambient," Advances in Soft Computing, vol. 51, pp. 112-116, 2009.

[64] P. C. Garrido et al., "Use of NFC-based Pervasive Games for Encouraging Learning and Student Motivation," in Proc. 3rd International Workshop on Near Field Communication, Hagenberg, Austria, pp. 33-37, 2011.

[65] I. Sánchez et al., "NFC-based Interactive Learning Environments for Children," in Proc. the 10th International Conference on Interaction Design and Children, pp. 205-208, 2011.

[66] M. Ervasti et al., "Bringing Technology into School - NFC-enabled School Attendance Supervision," in Proc. the 8th International Conference on Mobile and Ubiquitous Multimedia, 2009.

[67] M. Ervasti et al., "Experiences from NFC Supported School Attendance Supervision for Children," in Proc. Third International Conference on Mobile Ubiquitous Computing, Systems, Services and Technologies, Sliema, pp. 22-30, 2009.

[68] B. Sodor, G. Fordos, T. Doktor, and B. Benyo, "Building a contactless university examination system using NFC," in Proc. 15th IEEE International Conference on Intelligent Engineering Systems (INES), pp. 57-61, 2011.

[69] T. Ho and R. Chen, "Leveraging NFC and LBS Technologies to Improve User Experiences," in Proc. International Joint Conference on Service Sciences, Taiwan, pp. 17-21, 2011.

[70] B. Ozdenizci, K. Ok, V. Coskun, and M. Aydin, "Development of an Indoor Navigation System Using NFC Technology," in Proc. Fourth
International Conference on Information and Computing, Phuket Island, pp. 11-14, 2011.

[71] E. Siira, T. Tuikka, and V. Tormanen, "Location-based Mobile Wiki using NFC Tag Infrastructure," in Proc. the 1st International Workshop on Near Field Communication, Hagenberg, Austria, pp. 56-60.

[72] R. Ivanov, "Indoor Navigation System for Visually Impaired," in Proc. International Conference on Computer Systems and Technologies, Sofia, Bulgaria, 2010.

[73] S. Karpischek, F. Michahelles, F. Resatsch, and E. Fleisch, "Mobile Sales Assistant - An NFC-Based Product Information System for Retailers," in Proc. the 1st International Workshop on Near Field Communication, Hagenberg, Austria, pp. 20-23, 2009.

[74] F. Resatsch et al., "Mobile Sales Assistant - NFC for retailers," in Proc. the 9th International Conference on Human Computer Interaction with Mobile Devices and Services, pp. 313-316, 2007.

[75] X. Yiqun et al., "Sales Data Management System of Chain Enterprises Based on NFC Technology," in Proc. 2nd International Conference on Anti-counterfeiting, Security and Identification, Guiyang, pp. 455-458, 2008.

[76] S. Karpischek, F. Michahelles, A. Bereuter, and E. Fleisch, "A Maintenance System Based on Near Field Communication," in Proc. the 3rd International Conference on Next Generation Mobile Applications, Services and Technologies, Cardiff, Wales, UK, pp. 234-238, 2009.

[77] N. Kefalakis et al., "Supply Chain Management and NFC Picking Demonstrations using the AspireRfid Middleware Platform," in Proc. the ACM/IFIP/USENIX Middleware '08 Conference Companion, Leuven, Belgium, pp. 66-69, 2008.

[78] Z. Lou, "NFC Enabled Smart Postal System," in Proc. the 2nd International Workshop on Near Field Communication, Monaco, pp. 33-38, 2010

[79] P. Nepper, N. Konrad, and U. Sandner, "Talking Media," in Proc. 9th International Conference on Human Computer Interaction with Mobile Devices and Services, Singapore, 2007.

[80] K. Ok, V. Coskun, and M. N. Aydin, "Usability of Mobile Voting with NFC Technology," in Proc. IASTED International Conference on Software Engineering, Innsbruck, Austria, pp. 151-158, 2010.

[81] A. Wiethoff and G. Broll, "SoloFind: Chains of Interactions with a Mobile Retail Experience System," in Proc. the 2011 annual conference extended abstracts on Human factors in computing systems, Vancouver, BC, pp. 1303-1308, 2011.

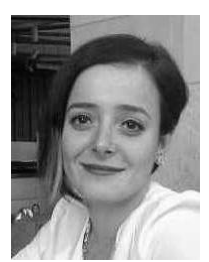

Busra Ozdenizci received her MS degree in Information Technologies from ISIK University, Turkey and currently studying her Ph.D. degree in Informatics. Her research areas include Near Field Communication, Mobile Communication Technologies and Mobile Persuasion. She has authored several conference and journal publications on NFC technology. She authored Near Field Communication: From Theory to Practice, which is published in 2012 by John Wiley \& Sons Inc. She is a researcher of NFC Lab - Istanbul.

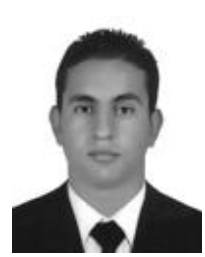

Mohammed Alsadi is currently studying his MS degree in Informatics department in Istanbul University. His research areas are Smart Card Technologies, Near Field Communication, Mobile Communication Technologies, and Mobile Programming. He is currently a researcher of NFC Lab - Istanbul.

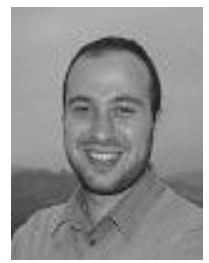

Kerem Ok is a Ph.D. candidate in Informatics department in Istanbul University, Turkey. His research areas are Near Field Communication, Mobile Communication Technologies, Android OS, and Mobile Usability. He has authored several conference and journal publications on NFC technology. He also authored one of the most comprehensive books on NFC technology in 2012, Near Field Communication: From Theory to Practice. He is currently a researcher of NFC Lab - Istanbul. 


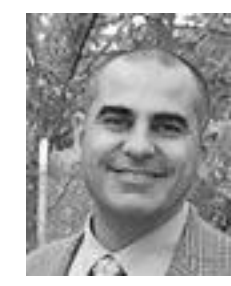

Vedat Coskun is a Computer Scientist, Academician, and Author. He established NFCLab - Istanbul (www.NFCLab.com), the leading and pioneer research lab on Near Field Communication (NFC) technology worldwide, which aims to take initiative on sustainable evolution of the technology for creating a win-win ecosystem for all the actors in the game such as users and financial and technical organizations. $\mathrm{He}$ is currently working as Associate Professor of Information Technology department in ISIK University, Istanbul. He received "Excellence in Teaching" award from ISIK University in 2012. He also gave lectures in several other universities such as University of Thessaly, Volos / Greece, Malardalen University, Vasteras / Sweden, Inholland University, Amsterdam / Netherlands. He is specialized in Security, Mobile Technologies, Java technology, Android, and NFC. He has vast amount of conference and journal publications. He authored several books, including Near Field Communication: From Theory to Practice, which is published in 2012 by John Wiley \& Sons Inc. He believes on the importance of academia $\&$ industry relationship, and takes role as consultant for national and international companies in this manner. 